\title{
Higher doses of cabergoline further improve metabolic parameters in patients with prolactinoma regardless of the degree of reduction in prolactin levels
}

\author{
Alessandro Ciresi, Marco Calogero Amato, Valentina Guarnotta, Flavia Lo Castro and Carla Giordano \\ Section of Endocrinology, Dipartimento Biomedico di Medicina Interna e Specialistica (Di.Bi.Mi.S), University of Palermo, Palermo, \\ Italy
}

\section{Summary}

Objective Currently available studies that fully analyse the metabolic parameters in patients with prolactinoma are scarce and discordant. The aim of this study was to evaluate the metabolic effects of cabergoline (CAB) treatment in patients with newly diagnosed prolactinoma in relation to disease control and $\mathrm{CAB}$ dosage.

Design This is a retrospective clinical-based therapy analysis.

Patients Forty-three patients with prolactinoma (eight men, 35 women), aged $33.65 \pm 11.23$ years, were evaluated metabolically at baseline and after 12 months of CAB treatment.

Measurements Body mass index (BMI), systolic and diastolic blood pressure, waist circumference (WC), lipid profile, haemoglobinA1c (HbA1c), glucose and insulin levels (and their areas under the curve, AUC) after an oral glucose tolerance test, homoeostasis model assessment of insulin resistance (Homa-IR) index, insulin sensitivity index (ISI) Matsuda, oral disposition index (DIo) and visceral adiposity index (VAI) were measured at baseline and after 12 months of treatment.

Results Twelve months of CAB reduced WC $(P<0 \cdot 001)$, total $(P=0.001)$ and low-density lipoprotein Iterol $(P<0.001)$, triglycerides $(P=0.024)$, fasting insulin $(P<0.001)$, AUC $_{\text {INSULIN }}$ $(P<0.001)$, HbAlc $(P=0.022)$, Homa-IR $(P<0.001)$ and VAI $(P<0.001)$, with a concomitant increase in high-density lipoprotein cholesterol $(P<0.001)$ and in ISI Matsuda $(P<0.001)$, regardless of the degree of reduction in prolactin levels. The patients receiving higher doses $(>0.50 \mathrm{mg} /$ week $)$ of $\mathrm{CAB}$ showed lower BMI $(P=0.009)$, fasting insulin $(P=0.001)$, Homa-IR $(P<0.001)$ and VAI $(P=0.018)$ and higher ISI Matsuda $(P=0.002)$ and DIo $(P=0.011)$, compared with those on lower doses.

Conclusions A significant metabolic improvement was observed in patients with prolactinoma after 12 months of CAB

Correspondence: Carla Giordano, Section of Endocrinology, Dipartimento Biomedico di Medicina Interna e Specialistica (Di.Bi.Mi.S), University of Palermo, Piazza delle Cliniche 2, Palermo 90127, Italy. Tel.: +39 091 6552109; Fax: +39091 6552123; E-mail: cgiordan@unipa.it treatment, especially when higher doses were used, highlighting the importance of considering the metabolic profile in these patients and the role of active treatment with high $\mathrm{CAB}$ doses.

(Received 14 January 2013; returned for revision 30 January 2013; finally revised 27 February 2013; accepted 14 March 2013)

\section{Introduction}

Prolactinoma is the most frequent secreting pituitary tumour and mainly affects the female gender. ${ }^{1}$ Besides the well-known consequences on the reproductive axis both in men and women, hyperprolactinaemia can be associated with alterations in body composition and obesity, ${ }^{2}$ although the evidence is discordant. Reduced bone density ${ }^{3,4}$ and total body fat ${ }^{5,6}$ have been positively associated with high prolactin (PRL) levels in patients with prolactinoma. Schmid et al. ${ }^{7}$ demonstrated significantly higher body mass index (BMI) in patients with macroprolactinoma than both patients with inactive adenomas and the general population. Conversely, Naliato et al. showed similar body fat in women with prolactinoma and controls. ${ }^{5}$

Dopamine agonists (DA) are recognized as the recommended therapy to lower PRL levels and decrease tumour size for patients with prolactinoma, and the use of cabergoline $(\mathrm{CAB})$ is suggested in preference to other DA because of its higher efficacy. ${ }^{8}$ Several studies have analysed the effects of DA treatment on body fat and metabolism, but most of them used mainly bromocriptine. ${ }^{9}$ In this setting, reduced body fat content and a lower risk of metabolic syndrome have been associated with the normalization of PRL during DA treatment. ${ }^{5}$ Decreased BMI and waist circumference (WC) have been reported during DA therapy in some studies, ${ }^{10}$ but not in others. ${ }^{11}$ However, currently available studies that fully analyse the metabolic parameters in patients with prolactinoma at diagnosis and during treatment with $\mathrm{CAB}$ are scarce, and discordant data have been reported. Based on the data that link the body composition parameters with PRL levels and DA administration, the aim of the current study was to fully evaluate the effects of 12 months of $\mathrm{CAB}$ treatment on the metabolic syndrome (MS), insulin 
sensitivity and visceral adiposity index (VAI), ${ }^{12}$ a surrogate parameter indicating adipose tissue dysfunction associated with cardiometabolic risk, in a group of patients with newly diagnosed prolactinoma in relation to disease control and $\mathrm{CAB}$ dosage.

\section{Patients and methods}

We conducted a retrospective chart review of patients affected by hyperprolactinaemia seen at the Unit of Endocrinology of the University of Palermo from 1 January 2011 to 30 October 2012. We analysed data from a total of 89 patients. The flow chart of patient distribution and inclusion in the study according to the criteria adopted is shown in Fig. 1.

Patients with hyperprolactinaemia secondary to drugs (including neuroleptics, antidepressants, opiates and gastrointestinal prokinetics) or mixed-secreting tumours, those already receiving dopamine agonists at the baseline visit and those with a followup of less than 12 months were excluded from this analysis. In addition, we excluded patients with multiple pituitary hormone deficiencies and/or the presence of other concomitant causes of overt hypogonadism to avoid the potential impact of hormonal deficit or gonadal replacement therapy on metabolic parameters. No women receiving oestrogens and/or progesterone as contraceptives or postmenopausal hormone replacement therapy were included. All patients with already known glucose abnormalities were treated with diet alone. Patients already receiving hypoglycaemic agents were excluded from this study. For the purpose of this study, we enrolled 43 consecutive patients ( 8 men, 19\%; 35 women, $81 \%$ ) aged $33.65 \pm 11.23$ years (range: 16-63), with newly diagnosed prolactinoma. The diagnosis was based on signs and symptoms of hyperprolactinaemia, high-serum PRL levels and magnetic resonance imaging (MRI) demonstrating a pituitary tumour. ${ }^{8}$ This study was conducted in compliance with the 'Ethical principles for medical research involving human subjects' of the Helsinki Declaration. At the time of hospitalization, all patients signed a consent form for the scientific use of their data and the identity of the participants remained anonymous during the analysis.

\section{Study design}

All patients, at baseline and after 12 months of CAB treatment, underwent a complete clinical and metabolic evaluation. Prolactin levels were considered as the mean value of measurements in at least three blood samples collected at 20-min intervals for $1 \mathrm{~h}$, obtained through venous cannulation, without repeated venepuncture stress. Women who presented with menstrual cycles, even if irregular, were studied in the early follicular phase (1-7 days from bleeding). In all patients, MRI revealed the presence of a pituitary tumour. Tumour volume was calculated in line with the Di Chiro and Nelson formula (volume $=$ height $\times$ length $\times$ width $\times \pi / 6)$ and was expressed as $\mathrm{mm}^{3}$. BMI and systolic (SBP) and diastolic (DBP) blood pressure were measured in all patients. WC was measured at the midpoint between the lower rib and the iliac crest. After an overnight fast, total, high-density lipoprotein (HDL) and

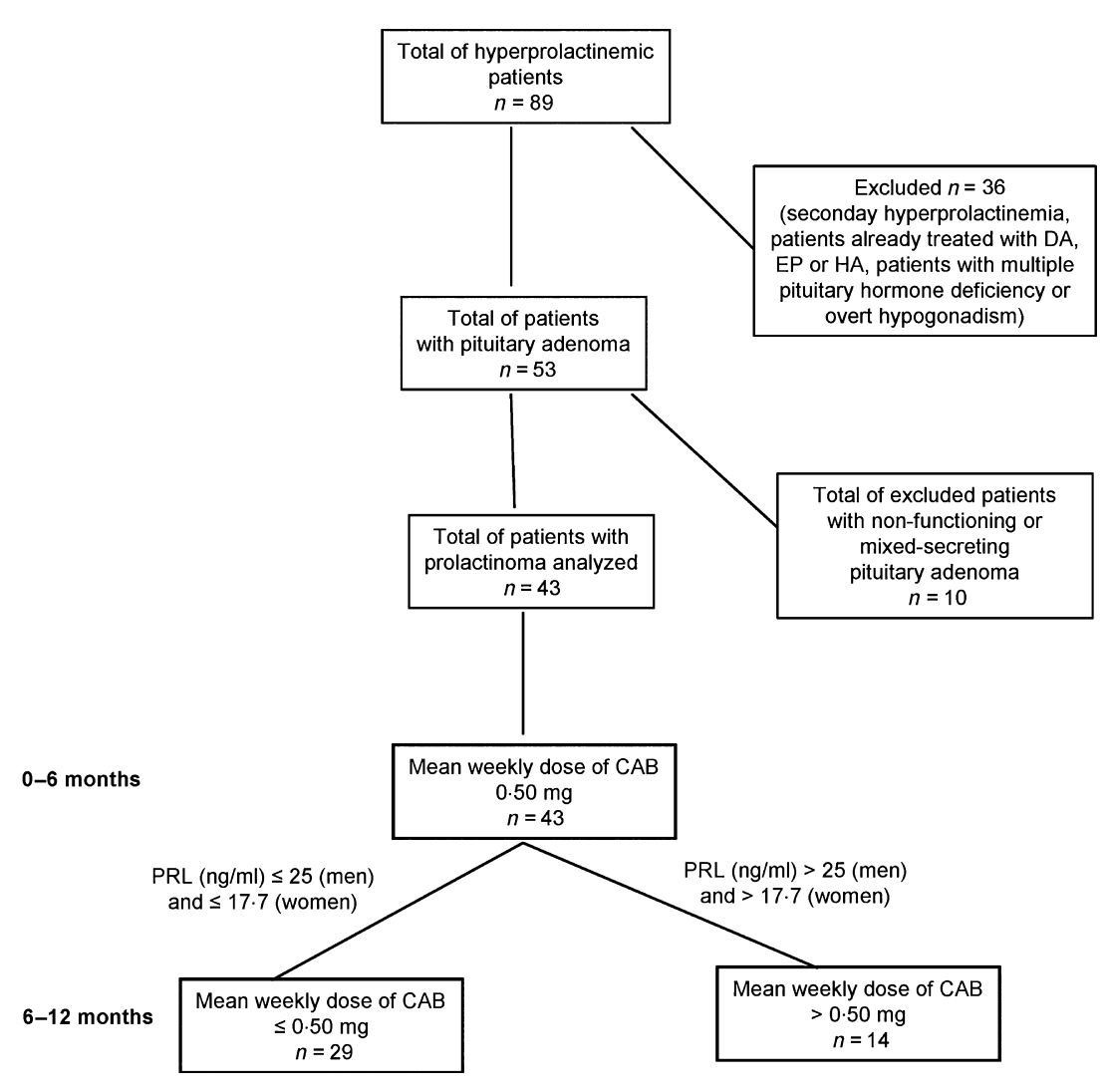

Fig. 1 Flow chart of patient distribution and inclusion in the study according to criteria adopted and dosage of cabergoline used. Dopamine agonists: dopamine agonists; EP: oestro/ progesterone; HA: hypoglycaemic agents; CAB: cabergoline; PRL: prolactin. 
low-density lipoprotein (LDL) cholesterol, triglycerides and haemoglobinAlc (HbA1c) were measured. In addition, an oral glucose tolerance test (OGTT) was performed by measuring plasma blood glucose and insulin levels every $30 \mathrm{~min}$ for $2 \mathrm{~h}$ after a 75-g oral glucose load. The areas under the curve of glucose $\left(\mathrm{AUC}_{\mathrm{GLU}}\right)$ and insulin $\left(\mathrm{AUC}_{\mathrm{INS}}\right)$ during the 2-h OGTT were also calculated. The diagnosis of diabetes or glucose tolerance abnormalities was made according to the American Association of Clinical Endocrinologists medical guidelines. ${ }^{13}$ Basal insulin resistance (IR) was assessed using homoeostasis model assessment of the insulin resistance (Homa-IR) index. ${ }^{14}$ Stimulated insulin sensitivity was measured using the insulin sensitivity index (ISI), a composite index derived from the OGTT and validated by Matsuda et al. ${ }^{15}$ Total insulin secretion was assessed by $\mathrm{AUC}_{\mathrm{INS}}$, while $\beta$-cell function relative to insulin sensitivity was assessed by oral disposition index (DIo). ${ }^{16}$

VAI was calculated as described, ${ }^{12}$ using the following formula differentiated according to sex, when TG is triglyceride level expressed in $\mathrm{mm}$ and HDL is HDL cholesterol level expressed in mм:

$$
\text { Men }: V A I=[W C / 39 \cdot 68+(1 \cdot 88 \times B M I)] \times(T G / 1 \cdot 03) \times(1 \cdot 31 / H D L)
$$$$
\text { Women:VAI }=[W C / 36 \cdot 58+(1.89 \times B M I)] \times(T G / 0 \cdot 81) \times(1.52 / H D L)
$$

After the diagnosis was made, all patients received $\mathrm{CAB}$ at the initial weekly dose of $0.50 \mathrm{mg}$ for the first 6 months. After this period, the $\mathrm{CAB}$ dose was adjusted to maintain serum PRL levels within the normal range for sex or was increased to the maximal tolerable dose for patients who did not achieve normal PRL levels or did not show significant tumour shrinkage. We considered disease control to be attained when PRL levels decreased to normal values for healthy subjects, according to gender (Fig. 1). The mean weekly dose used during the study period was $0 \cdot 58 \pm 0 \cdot 30 \mathrm{mg}$ (range: $0 \cdot 25-1 \cdot 80$ ).

\section{Hormone and biochemical assays}

Glucose and lipid (HDL, LDL and total cholesterol, triglycerides) levels were measured in our centralized laboratory by standard methods. Serum insulin was measured by ELISA (DRG Instruments $\mathrm{GmbH}$, Germany). The sensitivity of the methods was $1 \mathrm{mIU} / \mathrm{l}$. The normal insulin range (mIU/l) was 5-19. The conversion factor from conventional to SI units was 6.945. During the entire study period, serum PRL was measured by chemiluminescent assay (Immulite 2000; Diagnostic Products, Los Angeles, CA) with a sensitivity of $3.2 \mathrm{mU} / \mathrm{l}$. The intra- and interassay coefficients of variation were $2 \cdot 3$ and $5.9 \%$, respectively. Normal ranges were $38-500$ and $40-354 \mathrm{mU} / \mathrm{l}$ for women and men, respectively.

\section{Statistical analysis}

The Statistical Packages for Social Sciences SPSS version 17 were used for data analysis. All quantitative variables showed normal distribution (normality of distribution was assessed by the Kolmogorov-Smirnov test). Baseline and after-treatment variables were presented as mean \pm Standard Deviation (SD) for continuous variables; rates and proportions were calculated for categorical data. Differences between groups in univariate analysis were detected by the unpaired Student's $t$-test for continuous variables and by the chi-square test and Fisher's exact test (when appropriate) for categorical variables. The differences between paired continuous variables (before and after 12 months of therapy) were analysed by the paired Student's $t$-test for continuous variables and by the $\mathrm{McNemar}$ test for categorical variables. A $P$ value of $<0.05$ was considered statistically significant.

\section{Results}

\section{Baseline}

The hormonal and metabolic parameters of patients at diagnosis are shown in Table 1. The mean PRL levels at diagnosis were $3715 \pm 5718 \mathrm{mU} / \mathrm{l}$ with a mean tumour volume of

Table 1. Hormonal and metabolic parameters before and after 12 months of treatment with cabergoline

\begin{tabular}{|c|c|c|c|c|c|}
\hline & \multicolumn{4}{|c|}{$\begin{array}{l}\text { Patients with prolactinoma } \\
\text { (No. 43) }\end{array}$} & \multirow[b]{2}{*}{$P$} \\
\hline & \multicolumn{2}{|c|}{$\begin{array}{l}\text { Basal } \\
\text { Mean } \pm \mathrm{SD}\end{array}$} & \multicolumn{2}{|c|}{$\begin{array}{l}12 \text { months } \\
\text { Mean } \pm \text { SD }\end{array}$} & \\
\hline Tumour volume $\left(\mathrm{mm}^{3}\right)$ & \multicolumn{2}{|c|}{$10 \cdot 56 \pm 5 \cdot 19$} & \multicolumn{2}{|c|}{$8 \cdot 16 \pm 3 \cdot 58$} & $<0.001$ \\
\hline Prolactin $(\mathrm{mU} / \mathrm{l})$ & \multicolumn{4}{|c|}{ No. (\%) } & \\
\hline \multirow{5}{*}{\multicolumn{2}{|c|}{$\begin{array}{l}\text { Normal glucose tolerance (NGT) } \\
\text { Impaired fasting glucose (IFG) } \\
\text { Impaired glucose tolerance (IGT) } \\
\text { Diabetes mellitus (DM) } \\
\text { Metabolic syndrome }\end{array}$}} & \multicolumn{2}{|c|}{$27(62 \cdot 8)$} & $39(90 \cdot 7)$ & 0.004 \\
\hline & & \multicolumn{2}{|c|}{$5(11 \cdot 6)$} & $1(2 \cdot 3)$ & $0 \cdot 218$ \\
\hline & & \multicolumn{2}{|c|}{$10(23 \cdot 3)$} & $3(7)$ & 0.039 \\
\hline & & \multicolumn{2}{|c|}{$1(2 \cdot 3)$} & - & 1 \\
\hline & & \multicolumn{3}{|c|}{$13(30 \cdot 2)$} & 0.016 \\
\hline & \multicolumn{2}{|c|}{ Mean \pm SD } & \multicolumn{2}{|c|}{ Mean \pm SD } & \\
\hline BMI $\left(\mathrm{kg} / \mathrm{m}^{2}\right)$ & \multicolumn{2}{|c|}{$25 \cdot 57 \pm 5 \cdot 18$} & \multicolumn{2}{|c|}{$25.41 \pm 4.97$} & $0 \cdot 177$ \\
\hline $\mathrm{WC}(\mathrm{cm})$ & \multicolumn{2}{|c|}{$88 \cdot 81 \pm 10 \cdot 48$} & \multicolumn{2}{|c|}{$87 \cdot 13 \pm 10 \cdot 15$} & $<0.001$ \\
\hline Total cholesterol (mM) & \multicolumn{2}{|c|}{$4 \cdot 70 \pm 0.98$} & \multicolumn{2}{|c|}{$4 \cdot 30 \pm 0 \cdot 73$} & 0.001 \\
\hline HDL cholesterol (mм) & \multicolumn{2}{|c|}{$1 \cdot 19 \pm 0 \cdot 21$} & \multicolumn{2}{|c|}{$1 \cdot 28 \pm 0 \cdot 21$} & $<0.001$ \\
\hline LDL cholesterol (mM) & \multicolumn{2}{|c|}{$2 \cdot 85 \pm 0.93$} & \multicolumn{2}{|c|}{$2 \cdot 42 \pm 0.68$} & $<0.001$ \\
\hline Triglycerides (mM) & \multicolumn{2}{|c|}{$1.43 \pm 0.65$} & \multicolumn{2}{|c|}{$1 \cdot 30 \pm 0 \cdot 50$} & 0.024 \\
\hline Fasting glucose (mM) & \multicolumn{2}{|c|}{$5 \cdot 18 \pm 0 \cdot 81$} & \multicolumn{2}{|c|}{$5.33 \pm 0.99$} & $0 \cdot 337$ \\
\hline Fasting Insulin (pм) & \multicolumn{2}{|c|}{$117.98 \pm 46.89$} & \multicolumn{2}{|c|}{$86 \cdot 42 \pm 25 \cdot 90$} & $<0.001$ \\
\hline HbAlc (\%) & \multicolumn{2}{|c|}{$5 \cdot 36 \pm 0 \cdot 62$} & \multicolumn{2}{|c|}{$5 \cdot 18 \pm 0 \cdot 43$} & 0.022 \\
\hline Homa-IR & $3 \cdot 87=$ & 1.53 & & $93 \pm 0 \cdot 96$ & $<0.001$ \\
\hline Matsuda Index & $3 \cdot 20=$ & $1 \cdot 28$ & & $75 \pm 1 \cdot 44$ & $<0.001$ \\
\hline $\begin{array}{l}\text { AUC }_{2 \mathrm{hGlucose}} \\
(\mathrm{mM} ; 120 \mathrm{~min})\end{array}$ & 860 & 167 & & $40 \pm 161$ & $0 \cdot 357$ \\
\hline $\begin{array}{l}\mathrm{AUC}_{2 \mathrm{hInsulin}} \\
(\mathrm{pm} ; 120 \mathrm{~min})\end{array}$ & 58963 & 21286 & & $39 \pm 11249$ & $<0.001$ \\
\hline DIo & $1 \cdot 72=$ & 1.53 & & $2 \pm 2 \cdot 21$ & $0 \cdot 404$ \\
\hline $\begin{array}{l}\text { Visceral adiposity } \\
\text { index (VAI) }\end{array}$ & $2 \cdot 36=$ & $1 \cdot 32$ & & $94 \pm 1.01$ & $<0.001$ \\
\hline
\end{tabular}


$10 \cdot 56 \pm 5 \cdot 19 \mathrm{~mm}^{3}$. The mean BMI and WC values were $25 \cdot 57 \pm 5.18$ and $88 \cdot 81 \pm 10 \cdot 48$, respectively. Using the National Cholesterol Education Program (NCEP-Adult Treatment Panel III, ATP III) criteria, ${ }^{17}$ MS was found in 13 patients (30.2\%). Twenty-seven of 43 patients $(62 \cdot 8 \%)$ were classified as having normal glucose tolerance (NGT), 5 (11.6\%) impaired fasting glucose (IFG), 10 (23.3\%) impaired glucose tolerance (IGT) and only 1 patient had newly diagnosed overt diabetes mellitus (DM), according to the American Association of Clinical Endocrinologists medical guidelines. ${ }^{13}$ No correlation between PRL levels and BMI, CV, VAI and other metabolic parameters at diagnosis was found (data not shown).

\section{At 12 months of treatment}

The hormonal and metabolic parameters of patients after CAB treatment are shown in Table 1. As expected, at 12 months of treatment, a significant decrease in PRL levels $(529.2 \pm 712$ vs $3715 \pm 5718 \mathrm{mU} / \mathrm{l} ; \quad P=0.001)$ and tumour volume $(8.16 \pm 3.58$ vs $10.56 \pm 5.19 \mathrm{~mm} 3 ; P<0.001)$ was found. As a whole, 24 of 43 patients $(55 \cdot 8 \%)$ were classified as controlled and 19 of $43(44 \cdot 2 \%)$ as uncontrolled.

We found a significant increase in the prevalence of NGT (90.7 vs $62.8 \% ; P=0.004)$ with a concomitant decrease in cases of IGT (7 vs 23.3\%; $P=0.039$ ) and a trend to reduction in the cases of IFG, although not statistically significant $(2.3$ vs $11.6 \%$; $P=0 \cdot 218$ ). The single case of DM diagnosed at baseline was not confirmed after 12 months of treatment. MS was detected in 6 (14\%) patients versus 13 patients $(30 \cdot 2 \%)$ before treatment $(P=0.016)$. A significant decrease in WC $(87 \cdot 13 \pm 10 \cdot 15$ vs $88.81 \pm 10.48 \mathrm{~cm} ; P<0.001)$, without a significant decrease in BMI $\left(25 \cdot 41 \pm 4.97\right.$ vs $\left.25 \cdot 57 \pm 5 \cdot 18 \mathrm{~kg} / \mathrm{m}^{2} ; P=0 \cdot 177\right)$, was also found.

As regards the lipid profile, we found a significant decrease in total cholesterol $(4.30 \pm 0.73$ vs $4.70 \pm 0.98 \mathrm{~mm} ; P=0.001)$, LDL cholesterol $(2.42 \pm 0.68$ vs $2.85 \pm 0.93 \mathrm{~mm} ; P<0.001)$ and triglycerides $(1.30 \pm 0.50$ vs $1.43 \pm 0.65 \mathrm{~mm} ; P=0.024)$, with a concomitant significant increase in HDL cholesterol $(1.28 \pm 0.21$ vs $1.19 \pm 0.21 \mathrm{~mm} ; P<0.001)$.

As regards glucose metabolism, a significant reduction in fasting insulin $(86.42 \pm 25.90$ vs $117.98 \pm 46.89$ pM; $P<0.001)$, AUC $_{\text {INS }}(37739 \pm 11249$ vs $58963 \pm 21286 ; P<0.001)$, HbAlc $(5.18 \pm 0.43$ vs $5.36 \pm 0.62 \% ; \quad P=0.022)$ and Homa-IR $(2.93 \pm 0.96$ vs $3.87 \pm 1.53 ; \quad P<0.001)$ with a significant increase in ISI Matsuda $(4.75 \pm 1.44$ vs $3.20 \pm 1.28 ; P<0.001)$ was detected (Fig. 2a). VAI was significantly decreased $(1.94 \pm 1.01$ vs $2.36 \pm 1.32, P<0.001)$ after 12 months of treatment (Fig. 2d). No significant difference was found in fasting glucose $(P=0.337), \operatorname{AUC}_{\mathrm{GLU}}(P=0.357)$ and DIo $(P=0.404)$ (Fig. 2g). No correlation between PRL and BMI, $\mathrm{CV}$, VAI and other metabolic parameters was found at 12 months of treatment (data not shown).

When we analysed the hormonal and metabolic parameters in patients grouped according to achievement of disease control, the two groups only differed in PRL levels $(P<0.001)$ and tumour volume $(P=0 \cdot 016)$ (Table 2, Fig. 2b,e,h).
Grouping the patients according to median weekly dose of $\mathrm{CAB}$ used during the 12-month-follow-up $\left[\begin{array}{ll}0.50 & (0 \cdot 37-0 \cdot 75)\end{array}\right.$ $\mathrm{mg}$, those treated with a low dose (LD: $\leq 50$ th centile; i.e. $\leq$ $0.50 \mathrm{mg}$ ) were $29(67.4 \%)$ and those with a high dose (HD: $>50$ th centile; i.e. $>0 \cdot 50 \mathrm{mg}$ ) were $14(32 \cdot 6 \%)$. No difference was found in tumour volume $(P=0.625)$ or PRL levels $(P=0.430)$ between the two groups. MS was found in 1 patient $(7 \cdot 2 \%)$ receiving $\mathrm{HD}$ of $\mathrm{CAB}$ and in 5 patients $(17 \cdot 2 \%)$ on $\mathrm{LD}$ $(P=0 \cdot 645)$. NGT, IFG and IGT were found in $26(89 \cdot 6 \%)$ and $13(92 \cdot 8 \%), 0$ and $1(7 \cdot 2 \%), 3(10 \cdot 4 \%)$ and 0 patients receiving $\mathrm{HD}$ and LD, respectively, without significant differences between the two patient groups. The data of patients grouped according to $\mathrm{CAB}$ dose are shown in Table 3. The patients receiving HD showed lower BMI $\left(23.12 \pm 2.71\right.$ vs $26.51 \pm 5.45 \mathrm{Kg} / \mathrm{m}^{2}$; $P=0.009)$, fasting insulin $(69.20 \pm 17.67$ vs $94.73 \pm 25.33$; $P=0.001)$, Homa-IR $(2.21 \pm 0.64$ vs $3.28 \pm 0.90 ; P<0.001)$ and VAI $(1.31 \pm 0.44$ vs $2.07 \pm 1.11 ; P=0.018)$ (Fig. 2f) compared with those receiving $\mathrm{LD}$, with concomitant higher ISI Matsuda (5.70 \pm 1.28 vs $4.29 \pm 1.29 ; P=0.002)$ (Fig. 2c) and DIo (3.20 \pm 3.52 vs. $1.41 \pm 0.74 ; P=0.011)$.(Fig. $2 \mathrm{i})$. No difference in the other metabolic parameters was found between the two groups of patients.

\section{Discussion}

The role of PRL as a metabolic hormone and the metabolic effect of DA treatment in patients with prolactinoma are not fully understood. Our data demonstrate that 12 months of CAB treatment improves most of the metabolic parameters and the degree of glucose tolerance, mainly when higher doses of $\mathrm{CAB}$ are used.

In this study, a control group was not recruited as our aim was to evaluate the metabolic parameters during DA treatment, and for this purpose, we used patients as their own controls.

Weight gain and impaired lipid profile have frequently been associated with hyperprolactinaemia, and a link between elevated PRL levels and glucose abnormalities or hyperinsulinaemia has been well documented. ${ }^{18-21}$ The mechanisms of these associations are still poorly understood. The involvement of PRL in pancreatic $\beta$-cell and insulin production and secretion has been proposed, ${ }^{22,23}$ and a role of PRL in reducing lipoprotein lipase activity in adipose tissue with consequent increase in triglycerides has been demonstrated. ${ }^{24}$ An involvement of adipokines in prolactinoma has also been suggested. It is well known that leptin plays a major role in food intake and body energy balance, ${ }^{25}$ and Balci et al. recently demonstrated strong immunoreactivity for leptin protein in prolactinomas, assuming a cosecretion of PRL and leptin. ${ }^{26}$ These observations could partially explain some metabolic features observed in patients with prolactinoma, such as the presence of insulin resistance, although to date discordant data are available. Indeed, no correlation between PRL and leptin levels nor a decrease in leptin during DA treatment has been observed. ${ }^{11}$ Hypogonadism, which is frequently associated with hyperprolactinaemia, has been considered an additional possible mechanism involved in weight gain in these patients. ${ }^{27}$ For this reason, to avoid any 

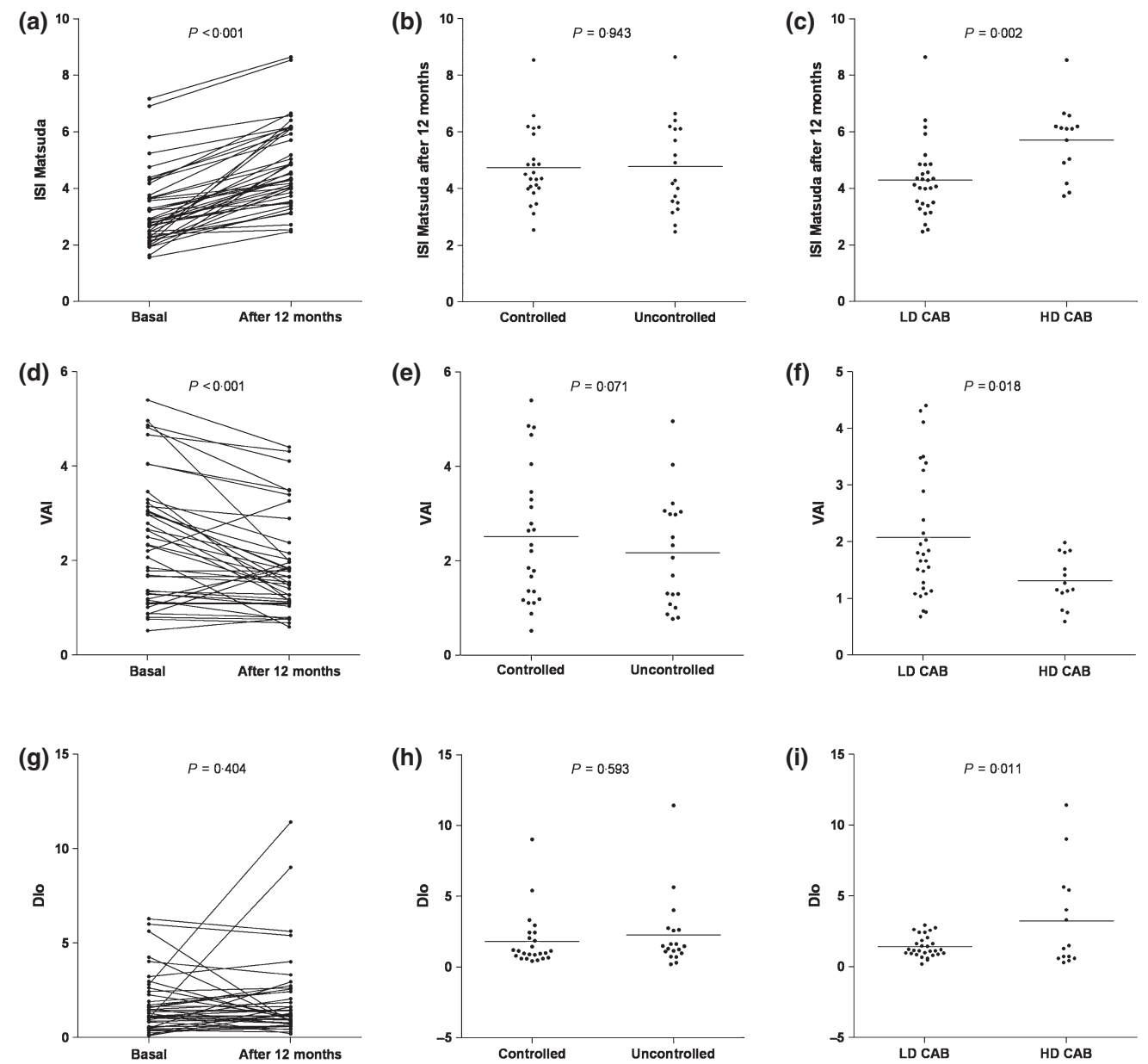

Fig. 2 Representation of insulin sensitivity index Matsuda, visceral adiposity index and oral disposition index (DIo) in patients with prolactinoma before and after cabergoline treatment (left), grouped according to control of the disease (in the middle) and according to cabergoline dosage used (right). CAB: cabergoline; LD: low dose; HD: high dose.

interference, we decided to exclude from this analysis patients with overt hypogonadism associated with prolactinoma. Recently, waist/hip ratio, lipid profile, Homa-IR and adiponectin levels were found significantly altered in 20 patients with prolactinoma with uncontrolled PRL levels compared with healthy subjects, ${ }^{28}$ and Tuzcu et al. ${ }^{29}$ demonstrated a state of insulin resistance in 16 patients with hyperprolactinaemia using a euglycaemic hyperinsulinaemic clamp. However, the reduced degree of insulin sensitivity described in patients with elevated PRL seems not to have any association with BMI or waist circumference. $^{30}$ Our results are in line with these findings. Indeed, in our patients, no association between PRL levels and metabolic parameters was found either at baseline or after 12 months of treatment with $\mathrm{CAB}$, and no difference in metabolic profile was found between patients with uncontrolled and controlled PRL levels during treatment. In this light, PRL seems not to be directly involved in the metabolic features of patients with prolactinoma. The absence of significant differences in metabolic parameters between patients with persistent high PRL levels and patients with controlled disease strengthens this hypothesis.
Dopamine has been shown to play a role in increased energy expenditure and downregulated food intake. ${ }^{31}$ The reduction in dopaminergic tone associated with hyperprolactinaemia has been considered as an additional possible mechanism involved in weight gain in patients with prolactinoma, and the lower body fat content in patients that normalizes the PRL levels is likely due to dopamine receptor type 2 (DR2) activation as a result of DA treatment. ${ }^{5}$ In this connection, it has been suggested that the DR2 gene may play a role in the regulation of weight. ${ }^{32}$ A role of DA in glucose and lipid metabolism has been well documented both in diabetic and obese subjects, ${ }^{33,34}$ but most of the available data are under bromocriptine treatment. ${ }^{35,36}$ For these reasons, we aimed to evaluate the $\mathrm{CAB}$ effect on metabolic parameters. Most of the available studies have focused on metabolic parameters such as weight or BMI, highlighting the prevalence of obesity in patients with prolactinoma, ${ }^{7}$ and the reduction in weight after the normalization of PRL levels during DA treatment ${ }^{2,37}$ although with discordant results. ${ }^{29,38}$ In our cohort of patients with hyperprolactinaemia, while WC significantly decreased after treatment, BMI did not change significantly, suggesting the presence of other factors influencing the improvement in metabolic parameters. 
Table 2. Hormonal and metabolic parameters of patients grouped according to control of disease after 12 months of treatment with cabergoline

\begin{tabular}{lllr}
\hline & $\begin{array}{l}\text { Controlled } \\
\text { patients } \\
\text { (No. 24) } \\
\text { Mean } \pm \text { SD }\end{array}$ & $\begin{array}{l}\text { Uncontrolled } \\
\text { patients (No. 19) } \\
\text { Mean } \pm \text { SD }\end{array}$ & $P$ \\
\hline $\begin{array}{l}\text { Tumor volume }\left(\mathrm{mm}^{3}\right) \\
\text { Prolactin }(\mathrm{mU} / \mathrm{l})\end{array}$ & $\begin{array}{l}6.95 \pm 2 \cdot 39 \\
143 \pm 110\end{array}$ & $\begin{array}{l}9.75 \pm 4 \cdot 29 \\
996 \pm 781\end{array}$ & $<0.016$ \\
\hline
\end{tabular}

\begin{tabular}{|c|c|c|c|}
\hline & No. $(\%)$ & No. $(\%)$ & \\
\hline Normal glucose tolerance (NGT) & $21(87 \cdot 5)$ & $18(94 \cdot 7)$ & $0 \cdot 618$ \\
\hline Impaired fasting glucose (IFG) & $1(4 \cdot 1)$ & - & 1 \\
\hline Impaired glucose tolerance (IGT) & $2(8 \cdot 3)$ & $1(5 \cdot 2)$ & 1 \\
\hline Diabetes mellitus (DM) & - & - & - \\
\hline \multirow[t]{2}{*}{ Metabolic syndrome } & $4(16 \cdot 6)$ & $2(10 \cdot 5)$ & 0.678 \\
\hline & Mean \pm SD & Mean \pm SD & \\
\hline BMI $\left(\mathrm{kg} / \mathrm{m}^{2}\right)$ & $25 \cdot 06 \pm 5 \cdot 42$ & $25 \cdot 86 \pm 4 \cdot 43$ & 0.596 \\
\hline $\mathrm{WC}(\mathrm{cm})$ & $87 \cdot 25 \pm 9 \cdot 25$ & $87 \pm 11 \cdot 45$ & 0.939 \\
\hline Total cholesterol (mм) & $4 \cdot 22 \pm 0 \cdot 74$ & $4 \cdot 40 \pm 0 \cdot 72$ & $0 \cdot 450$ \\
\hline HDL cholesterol (mм) & $1 \cdot 26 \pm 0 \cdot 21$ & $1 \cdot 30 \pm 0 \cdot 21$ & $0 \cdot 510$ \\
\hline LDL cholesterol $(\mathrm{mm})$ & $2 \cdot 34 \pm 0.73$ & $2 \cdot 51 \pm 0.63$ & $0 \cdot 412$ \\
\hline Triglycerides (mм) & $1.34 \pm 0.55$ & $1 \cdot 25 \pm 0 \cdot 43$ & 0.537 \\
\hline Fasting glucose $(\mathrm{mm})$ & $5 \cdot 30 \pm 0 \cdot 57$ & $5 \cdot 36 \pm 1 \cdot 36$ & $0 \cdot 869$ \\
\hline Fasting Insulin (pм) & $85 \cdot 94 \pm 23 \cdot 24$ & $87 \cdot 03 \pm 29 \cdot 58$ & $0 \cdot 896$ \\
\hline HbAlc (\%) & $5 \cdot 15 \pm 0 \cdot 43$ & $5 \cdot 22 \pm 0 \cdot 43$ & 0.597 \\
\hline Homa-IR & $2.93 \pm 0.93$ & $2.92 \pm 1.02$ & $0 \cdot 982$ \\
\hline Matsuda Index & $4.73 \pm 1.31$ & $4.77 \pm 1.62$ & $0 \cdot 936$ \\
\hline AUC $_{2 \mathrm{hGlucose}}(\mathrm{mm} ; 120 \mathrm{~min})$ & $821 \pm 120$ & $862 \pm 204$ & $0 \cdot 444$ \\
\hline $\operatorname{AUC}_{2 \mathrm{hInsulin}}(\mathrm{pm} ; 120 \mathrm{~min})$ & $36561 \pm 7811$ & $39227 \pm 14599$ & $0 \cdot 447$ \\
\hline Oral Disposition Index (DIo) & $1.79 \pm 1.92$ & $2 \cdot 25 \pm 2 \cdot 57$ & 0.521 \\
\hline Visceral adiposity index (VAI) & $2 \cdot 05 \pm 1 \cdot 17$ & $1.53 \pm 0.66$ & 0.096 \\
\hline
\end{tabular}

The available studies on the effect of DA on lipid metabolism are not fully consistent. ${ }^{38,39} \mathrm{We}$ found a significant improvement in lipid profile, as demonstrated by the increase in HDL cholesterol and the decrease in LDL cholesterol and triglycerides, in line with the data of Berinder et al. ${ }^{10}$

The mechanisms by which DA could improve glucose metabolism may include suppression of endogenous glucose production or increased splanchnic glucose uptake after glucose ingestion. ${ }^{36}$ A tendency to an improvement in insulin sensitivity, assessed by both ISI Matsuda and clamp, was reported after DA treatment. ${ }^{9,10}$ These findings are concordant with our results. Indeed, we observed a significant improvement in glucose tolerance and prevalence of MS, with a decrease in insulin levels, an improvement in insulin sensitivity indices and a concomitant reduction in HbAlc. The improvement of the sole case of DM after 12 months of treatment, without glucose lowering treatment, is in line with previous data. ${ }^{10}$ Our data demonstrated that the relationship between the decrease in PRL levels and the improvement in insulin sensitivity and the other metabolic parameters seems to reflect the effect of $\mathrm{CAB}$ treatment, rather than the association between PRL and BMI. Because our patients did not show signifi-
Table 3. Hormonal and metabolic parameters of patients grouped according to cabergoline dosage after 12 months of treatment

\begin{tabular}{|c|c|c|c|}
\hline & $\begin{array}{l}\text { Patients under } \\
\text { high-dose } \\
\text { cabergoline } \\
\text { (No. 14) } \\
\text { Mean } \pm \text { SD }\end{array}$ & $\begin{array}{l}\text { Patients under low- } \\
\text { dose cabergoline } \\
\text { (No. 29) } \\
\text { Mean } \pm \text { SD }\end{array}$ & $P$ \\
\hline $\begin{array}{l}\text { Tumour volume }\left(\mathrm{mm}^{3}\right) \\
\text { Prolactin }(\mathrm{mU} / \mathrm{l})\end{array}$ & $\begin{aligned} 8 \cdot 66 & \pm 4 \cdot 77 \\
683 & \pm 965\end{aligned}$ & $\begin{array}{l}7 \cdot 92 \pm 2 \cdot 94 \\
449 \pm 544\end{array}$ & $\begin{array}{l}0.625 \\
0.430\end{array}$ \\
\hline Prolactin $(\mathrm{mU} / \mathrm{l})$ & No. (\%) & No. $(\%)$ & \\
\hline $\begin{array}{l}\text { Normal glucose tolerance } \\
(\mathrm{NGT})\end{array}$ & $13(92 \cdot 8)$ & $26(89 \cdot 6)$ & 1 \\
\hline Impaired fasting glucose (IFG) & $1(7 \cdot 2)$ & - & $0 \cdot 326$ \\
\hline $\begin{array}{l}\text { Impaired glucose tolerance } \\
\text { (IGT) }\end{array}$ & - & $3(10 \cdot 4)$ & 0.539 \\
\hline Diabetes mellitus (DM) & - & - & - \\
\hline \multirow[t]{2}{*}{ Metabolic syndrome } & $1(7 \cdot 2)$ & $5(17 \cdot 2)$ & $0 \cdot 645$ \\
\hline & Mean $\pm \mathrm{SD}$ & Mean \pm SD & \\
\hline BMI $\left(\mathrm{kg} / \mathrm{m}^{2}\right)$ & $23 \cdot 12 \pm 2 \cdot 71$ & $26 \cdot 51 \pm 5 \cdot 45$ & 0.009 \\
\hline $\mathrm{WC}(\mathrm{cm})$ & $84 \cdot 14 \pm 7 \cdot 10$ & $88 \cdot 58 \pm 11 \cdot 16$ & $0 \cdot 182$ \\
\hline Total cholesterol (mM) & $4.45 \pm 0.62$ & $4 \cdot 23 \pm 0 \cdot 78$ & $0 \cdot 321$ \\
\hline HDL cholesterol (mм) & $1.33 \pm 0.26$ & $1.25 \pm 0 \cdot 18$ & $0 \cdot 324$ \\
\hline LDL cholesterol (mм) & $2 \cdot 57 \pm 0 \cdot 58$ & $2.34 \pm 0.72$ & $0 \cdot 282$ \\
\hline Triglycerides (mM) & $1 \cdot 18 \pm 0 \cdot 42$ & $1.36 \pm 0.53$ & $0 \cdot 243$ \\
\hline Fasting glucose (mм) & $4.99 \pm 0.61$ & $5 \cdot 49 \pm 1 \cdot 10$ & $0 \cdot 067$ \\
\hline Fasting insulin (pм) & $69 \cdot 20 \pm 17 \cdot 67$ & $94 \cdot 73 \pm 25 \cdot 33$ & 0.001 \\
\hline HbAlc (\%) & $5 \cdot 01 \pm 0 \cdot 38$ & $5 \cdot 26 \pm 0 \cdot 43$ & $0 \cdot 070$ \\
\hline Homa-IR & $2 \cdot 21 \pm 0 \cdot 64$ & $3 \cdot 28 \pm 0 \cdot 90$ & $<0 \cdot 001$ \\
\hline Matsuda Index & $5 \cdot 70 \pm 1 \cdot 28$ & $4.29 \pm 1.29$ & 0.002 \\
\hline AUC $_{2 h \text { hlucose }}(\mathrm{mm} ; 120 \mathrm{~min})$ & $790 \pm 105$ & $864 \pm 179$ & 0.099 \\
\hline $\operatorname{AUC}_{2 h I n s u l i n ~}(\mathrm{pm} ; 120$ min) & $34354 \pm 9431$ & $39373 \pm 11834$ & $0 \cdot 143$ \\
\hline $\begin{array}{l}\text { Oral Disposition Index } \\
\text { (DIo) }\end{array}$ & $3 \cdot 20 \pm 3 \cdot 52$ & $1.41 \pm 0.74$ & $0 \cdot 011$ \\
\hline $\begin{array}{l}\text { Visceral adiposity index } \\
\text { (VAI) }\end{array}$ & $1 \cdot 31 \pm 0.44$ & $2 \cdot 07 \pm 1 \cdot 11$ & $0 \cdot 018$ \\
\hline
\end{tabular}

cant changes in BMI, other mechanisms seem to be involved in the beneficial effects of DA treatment on metabolic profile. In this light, the role of VAI cannot be ruled out. VAI is a sex-specific mathematical index based on anthropometric and metabolic parameters and could be considered a surrogate marker of adipose tissue function and distribution. This index has been demonstrated to be independently correlated with insulin sensitivity and cardiometabolic risk in the general population, ${ }^{12}$ in women with polycystic ovary syndrome ${ }^{40}$ and in newly diagnosed patients with acromegaly, where VAI significantly correlates with adipocytokine levels. ${ }^{41}$ After CAB treatment, our patients had significantly reduced VAI. Therefore, an improvement in adipose tissue function could be considered to have a major role in the change in metabolic profile after treatment. In this light, in line with previous studies, the improvement in insulin sensitivity after DA treatment could be considered to be linked to the decrease in PRL levels, to the improvement of body composition, as 
demonstrated by the reduction in WC and VAI, to DA treatment or to a combination of these factors. In this connection, our data show that patients treated with $\mathrm{HD}$ of $\mathrm{CAB}$ had a more marked improvement in metabolic profile, highlighted by BMI, insulin, Homa-IR, ISI Matsuda and VAI values, than patients treated with LD. In addition, the first group of patients showed higher DIo, demonstrating a more efficient and adequate insulin secretion relative to insulin sensitivity.

In conclusion, a significant metabolic improvement is observed in patients with prolactinoma after 12 months of $\mathrm{CAB}$ treatment and the reason for this is probably multifactorial. Our data highlight the importance of considering the metabolic profile in these patients and the role of active treatment with high $\mathrm{CAB}$ doses which, besides normalizing hormonal levels, also improve metabolic parameters and insulin sensitivity indices.

\section{Conflicting Interest}

The authors state that there is no potential conflict of interest.

\section{Financial Disclosure}

The authors have nothing to declare.

\section{References}

1 Gillam, M.P., Molitch, M.E., Lombardi, G. et al. (2006) Advances in the treatment of prolactinomas. Endocrine Reviews, 27, 485-534.

2 Greenman, Y., Tordjman, K. \& Stern, N. (1998) Increased body weight associated with prolactin secreting pituitary adenomas: weight loss with normalization of prolactin levels. Clinical Endocrinology, 48, 547-553.

3 Biller, B.M., Baum, H.B., Rosenthal, D.I. et al. (1992) Progressive trabecular osteopenia in women with hyperprolactinemia amenorrhea. The Journal of Clinical Endocrinology and Metabolism, 75, 692-697.

4 Naliato, E.C., Violante, A.H., Caldas, D. et al. (2008) Bone density in women with prolactinoma treated with dopamine agonists. Pituitary, 11, 21-28.

5 Naliato, E.C., Violante, A.H., Caldas, D. et al. (2007) Body fat in nonobese women with prolactinoma treated with dopamine agonists. Clinical Endocrinology, 67, 845-852.

6 Naliato, E.C., Violante, A.H., Gaccione, M. et al. (2008) Body fat in men with prolactinoma. Journal of Endocrinological Investigation, 31, 985-990.

7 Schmid, C., Goede, D.L., Hauser, R.S. et al. (2006) Increased prevalence of high Body Mass Index in patients presenting with pituitary tumours: severe obesity in patients with macroprolactinoma. Swiss Medical Weekly, 136, 254-258.

8 Melmed, S., Casanueva, F.F., Hoffman, A.R. et al. (2011) Diagnosis and treatment of hyperprolactinemia: an Endocrine Society clinical practice guideline. The Journal of Clinical Endocrinology and Metabolism, 96, 273-288.

9 Yavuz, D., Deyneli, O., Akpinar, I. et al. (2003) Endothelial function, insulin sensitivity and inflammatory markers in hyperprolactinemic pre-menopausal women. European Journal of Endocrinology, 149, 187-193.
10 Berinder, K., Nyström, T., Höybye, C. et al. (2011) Insulin sensitivity and lipid profile in prolactinoma patients before and after normalization of prolactin by dopamine agonist therapy. Pituitary, 14, 199-207.

11 dos Santos Silva, C.M., Barbosa, F.R., Lima, G.A. et al. (2011) BMI and metabolic profile in patients with prolactinoma before and after treatment with dopamine agonists. Obesity, 19, 800-805.

12 Amato, M.C., Giordano, C., Galia, M. et al. (2010) Visceral Adiposity Index (VAI): a reliable indicator of visceral fat function associated with cardiometabolic risk. Diabetes Care, 33, 920-922.

13 American Association of Clinical Endocrinologists. (2000) The American Association of Clinical Endocrinologists Medical Guidelines for the Management of Diabetes Mellitus: the AACE system of intensive diabetes self-management-2000 update. Endocrine Practice, 6, 43-84.

14 Matthews, D.R., Hosker, J.P., Rudenski, A.S. et al. (1985) Homeostasis model assessment: insulin resistance and b-cell function from fasting plasma glucose and insulin in man. Diabetologia, 28, 412-419.

15 Matsuda, M. \& De Fronzo, R.A. (2001) Insulin sensitivity indices obtained from oral glucose tolerance testing: comparison with the euglycemic insulin clamp. Diabetes Care, 24, 460-464.

16 Utzschneider, K.M., Prigeon, R.L., Faulenbach, M.V. et al. (2009) Oral disposition index predicts the development of future diabetes above and beyond fasting and 2 -h glucose levels. Diabetes Care, 32, 335-341.

17 Expert Panel on Detection, Evaluation, and Treatment of High Blood Cholesterol in Adults. (2001) Executive Summary of The Third Report of The National Cholesterol Education Program (NCEP) Expert Panel on Detection, Evaluation, and Treatment of High Blood Cholesterol in Adults (Adult Treatment Panel III). Journal of the American Medical Association, 285, 2486-2497.

18 Ben-Jonathan, N., Hugo, E.R., Brandebourg, T.D. et al. (2006) Focus on prolactin as a metabolic hormone. Trends in Endocrinology \& Metabolism, 17, 110-116.

19 Landgraf, R., Landraf-Leurs, M.M., Weissmann, A. et al. (1977) Prolactin: a diabetogenic hormone. Diabetologia, 13, 99-104.

20 Johnston, D.G., Alberti, K.G., Nattrass, M. et al. (1980) Hyperinsulinaemia in hyperprolactinaemic women. Clinical Endocrinology, 13, 361-368.

21 Pelkonen, R., Nikkilä, E.A. \& Grahne, B. (1982) Serum lipids, postheparin plasma lipase activities and glucose tolerance in patients with prolactinoma. Clinical Endocrinology, 16, 383-390.

22 Maccario, M., Grottoli, S., Razzore, P. et al. (1996) Effects of glucose load and/or arginine on insulin and growth hormone secretion in hyperprolactinemia and obesity. European Journal of Endocrinology, 135, 205-210.

23 Fleenor, D.E. \& Freemark, M. (2001) Prolactin induction of insulin gene transcription: roles of glucose and signal transducer and activator of transcription 5. Endocrinology, 142, 2805-2810.

24 Ling, C., Svensson, L., Odén, B. et al. (2003) Identification of functional prolactin (PRL) receptor gene expression: PRL inhibits lipoprotein lipase activity in human white adipose tissue. The Journal of Clinical Endocrinology and Metabolism, 88, 1804-1808.

25 Korbonits, M., Chitnis, M.M., Gueorguiev, M. et al. (2001) The release of leptin and its effect on hormone release from human pituitary adenomas. Pituitary, 4, 49-55.

26 Balci, H., Akgun-Dar, K., Gazioglu, N. et al. (2009) The relationship between prolactin (PRL), leptin, nitric oxide (NO), and 
cytokines in patients with hyperprolactinemia. Pituitary, 12, 170-176.

27 Tchernof, A., Poehlman, E.T. \& Després, J.P. (2000) Body fat distribution, the menopause transition, and hormone replacement therapy. Diabetes \& Metabolism, 26, 12-20.

28 de Assunção Alves Rodrigues, L.F., Campos, S.M., Miranda, P.A. et al. (2012) Prolactinoma: a condition associated with hypoadiponectinemia. Hormone and Metabolic Research, 44, 832-838.

29 Tuzcu, A., Yalaki, S., Arikan, S. et al. (2009) Evaluation of insulin sensitivity in hyperprolactinemic subjects by euglycemic hyperinsulinemic clamp technique. Pituitary, 12, 330-334.

30 Tuzcu, A., Bahceci, M., Dursun, M. et al. (2003) Insulin sensitivity and hyperprolactinemia. Journal of Endocrinological Investigation, 26, 341-346.

31 Ben-Jonathan, N. \& Hnasko, R. (2001) Dopamine as a prolactin (PRL) inhibitor. Endocrine Reviews, 22, 724-763.

32 Comings, D.E., Flanagan, S.D., Dietz, G. et al. (1993) The dopamine D2 receptor (DRD2) as a major gene in obesity and height. Biochemical Medicine and Metabolic Biology, 50, 176-185.

33 Cincotta, A.H., Meier, A.H. \& Cincotta Jr, M. (1999) Bromocriptine improves glycaemic control and serum lipid profile in obese Type 2 diabetic subjects: a new approach in the treatment of diabetes. Expert Opinion on Investigational Drugs, 8, 16831707.

34 Cincotta, A.H. \& Meier, A.H. (1996) Bromocriptine (Ergoset) reduces body weight and improves glucose tolerance in obese subjects. Diabetes Care, 19, 667-670.
35 Kamath, V., Jones, C.N., Yip, J.C. et al. (1997) Effects of a quick-release form of bromocriptine (Ergoset) on fasting and postprandial plasma glucose, insulin, lipid, and lipoprotein concentrations in obese nondiabetic hyperinsulinemic women. Diabetes Care, 20, 1697-1701.

36 Pijl, H., Ohashi, S., Matsuda, M. et al. (2000) Bromocriptine: a novel approach to the treatment of type 2 diabetes. Diabetes Care, 23, 1154-1161.

37 Doknic, M., Pekic, S., Zarkovic, M. et al. (2002) Dopaminergic tone and obesity: an insight from prolactinomas treated with bromocriptine. European Journal of Endocrinology, 147, 77-84.

38 Serri, O., Li, L., Mamputu, J.C. et al. (2006) The influences of hyperprolactinemia and obesity on cardiovascular risk markers: effects of cabergoline therapy. Clinical Endocrinology, 64, 366-370.

39 Fahy, U., Hopton, M.I., Hartog, M. et al. (1999) The lipoprotein profile of women with hyperprolactinaemic amenorrhoea. Human Reproduction, 14, 285-287.

40 Amato, M.C., Verghi, M., Galluzzo, A. et al. (2011) The oligomenorrhoic phenotypes of polycystic ovary syndrome are characterized by a high visceral adiposity index: a likely condition of cardiometabolic risk. Human Reproduction, 26, 14861494.

41 Ciresi, A., Amato, M.C., Pizzolanti, G. et al. (2012) Visceral adiposity index is associated with insulin sensitivity and adipocytokine levels in newly diagnosed acromegalic patients. The Journal of Clinical Endocrinology and Metabolism, 97, 2907-2915. 